\title{
Effect of different solvents and clay loading on Polyacrylamide hydrogel to remove Iron from Lean Methyldiethanol solvent
}

\author{
Priyabrata Pal ${ }^{1}$, Safa Gaber ${ }^{2}$, Mohammad Abu Haija ${ }^{2}$ and Fawzi Banat ${ }^{1 \star}$ \\ ${ }^{\prime}$ Department of Chemical Engineering, Khalifa University of Science and Technology, Abu Dhabi, United Arab Emirates \\ ${ }^{2}$ Department of Chemistry, Khalifa University of Science and Technology, Abu Dhabi, United Arab Emirates
}

\section{Article Info}

*Corresponding author:
Fawzi Banat
Professor
Department of Chemical Engineering
Khalifa University of Science and
Technology
Abu Dhabi, United Arab Emirates
E-mail: fbanat@pi.ac.ae

Received: March 9, 2017

Accepted: March 22, 2017

Published: March 27, 2017

Citation: Pal P, Gaber S, Haija MA, Banat F. Effect of different solvents and clay loading on Polyacrylamide hydrogel to remove Iron from Lean Methyldiethanol solvent. Int J Petrochem Res. 2017; 1(1): 6-11. doi: 10.18689/ijpr-1000102

Copyright: (c) 2017 The Author(s). This work is licensed under a Creative Commons Attribution 4.0 International License, which permits unrestricted use, distribution, and reproduction in any medium, provided the original work is properly cited.

Published by Madridge Publishers

\begin{abstract}
The polyacrylamide (PAAM) hydrogel consisting of acrylamideand 2(methacryloyloxy) ethyl aceto acetate as monomer, N, N'-methylenebisacrylamide as crosslinker and ammonium peroxodisulfate as initiator was prepared using different solvents. Methanol, ethanol, dimethylsulfoxide and deionized water was used as solvent to prepare the hydrogel. Its usefulness as adsorbent for the removal of iron as contaminants from industrial lean methyl diethanol amine solvents (MDEA, 50 weight \% used by GASCO Company, Abu Dhabi for natural gas sweetening) was tested. Finally, PAAM hydrogel in water with nitric acid treated sepiolite having different loading were prepared to increase the mechanical strength of the composite hydrogel. SEM and FTIR analysis of the PAAM clay composite hydrogel explained the morphology and adsorption process. PAAM composite hydrogel with $12.5 \%$ clay loading was found to be best using batch adsorption studies for the removal of iron (45.15\% having uptake capacity $6.397 \mu \mathrm{g} / \mathrm{g}$ using $1.0 \mathrm{~g}$ hydrogel) from industrial lean MDEA solvent.
\end{abstract}

Keywords: Gas sweetening; hydrogel; effect of solvent; clay loading; adsorption

\section{Introduction}

GASCO Company, Abu Dhabi is currently using methyldiethanolamine (MDEA, 50 weight \%) as solvent to remove $\mathrm{H}_{2} \mathrm{~S} / \mathrm{CO}_{2}$ from natural gas. In this process, reaction between aerial oxygen and $\mathrm{H}_{2} \mathrm{~S} / \mathrm{CO}_{2}$ with MDEA produces low molecular weight organic acid anions such as formate, acetate, propionate etc. These anionic species and protonated MDEA makes heat stable salt (HSS) which is not possible to be separated from the solvents in the regenerator [1] [2]. Accumulation of HSS continuously in the lean solvent deteriorates its quality making less sensitive for absorption. The increase in HSS also leads to foaming in the process as well as corrosion and fouling of the process equipment [3] [4] [5]. To maintain 50 weight \% MDEA solution, make-up water as well as fresh MDEA are added frequently in the process. Also, heavy metal ions such as iron, chromium, lead etc.is another class of contaminants found in lean MDEA solvents. It is coming mostly due to metal corrosion and erosion in the process. The heavy metal ions present in lean MDEA samples was mainly iron ranging from 900-1500 $\mu \mathrm{g} / \mathrm{g}$ as found in different batches [6]. Accumulation of iron as metal ions due to corrosion in running plant enhance foaming issues [7]. Iron complexing with MDEA degradation products also causes corrosion [8]. Again, iron produces soluble complex in alkanolamine solution saturated with carbon dioxide supports dissolution of steel surfaces [9]. Foaming tendency was increased by addition of 0.235 weight \% ferrous sulfide on 50 weight $\%$ 
MDEA [10]. The functional groups in MDEA (tertiary amine and hydroxyl) is easily attached with heavy metal ions using chelation. Thus, adsorbent like activated carbon cannot remove heavy metal ions overcoming this complexation. Currently, GASCO Company is using commercially available activated carbon as adsorbent to remove mostly HSS anions. Few attempts were tried to remove HSS anions and metal ions from alkanolamine solutions using distillation and electrodialysis [11] [12] [13]. These processes suffer serious setbacks in utility requirements in terms of continuous supply of huge volumes of waterand no more a cost efficient process

From last decade, polymeric hydrogel showed superior quality in removing different types of inorganic (such as chromium, lead, cobalt etc.) as well as organic pollutants using adsorption [14] [15]. The adsorption mainly results from the presence of large number of functional groups remain in the polymeric hydrogel network [16]. The presence of specific functional groups (such as $-\mathrm{OH}_{1}-\mathrm{NH}_{2^{\prime}}-\mathrm{SO}_{3} \mathrm{H}_{1}-\mathrm{COOH},-\mathrm{CONH}_{2}$ etc.) in hydrogel networks enables adsorptive removal of pollutants [17]. In recent studies, it was observed that hydrogels have superiority over conventional adsorbents like carbon in terms of adsorption capacity [18]. Hydrogels are similar to ion-exchange resins in many respects; for instance, they are polymeric materials and mostly remove pollutants through electrostatic interactions. However, resins have rigid structures while the structures of hydrogels are flexible and can imbibe much more pollutants compared to resins [19]. The pollutants can be adsorbed onto the outer surface as well as in the swollen three dimensional network of hydrogels. It has been shown that hydrogel properties can be varied by controlling the synthesis parameters, such as amount of monomers reaction time, temperature, and solvent used to prepare hydrogels [20]. Advantages of using hydrogel as adsorbents are due to its easy loading, reusability and the possibility of continuous operation [21] [22]. High swelling and wettability of the hydrogel also facilitates adsorption as the swelling of the three-dimensional networks allots high surface area and more exposed functional groups easily approachable for adsorption [23]. Hydrogels are generally prepared by copolymerization and crosslinking of functional monomers. Solvent has enormous role while producing polymeric hydrogels in terms of structure and morphology of the three dimensional network [24]. Even, mixed solvents like water and tetrahydrofuran were used to modulate polymerization and cross-linking of $\mathrm{N}$-isopropylacrylamide to obtain useful three dimensional hydrogel structure [25]. Most of the works using hydrogel beads as adsorbents usually focus on physicochemical and textural characterization, but very few has dealt with the mechanical properties of the hydrogels. These properties are relevant in order to select the type of equipment and the best operating conditions to achieve good adsorption performance at full-scale.

Hydrogel as adsorbents should be able to sustain the load they will be subjected to during handling and adsorption; consequently, an important issue is to determine if deformation affects their use, by reducing the voidage of flattened beads or increasing the resistance of the flow of liquids around them [26]. However, few studies have taken into account the presence of fillers in the hydrogel matrix affects the final characteristics of the beads. The latter is particularly important for their further commercialization as adsorbents. Moreover, mechanical strength of polymeric beads remains almost unexplored. Recently, the compression strength of alginate hydrogel cylinders reinforced with $\mathrm{GO}$ to the alginate matrix has been studied [27]. Mostly, clay composite hydrogels show good mechanical strength and used effectively as adsorbents for the removal of contaminants from solutions [28]. Sepiolite is one of the easily available low cost clay is being used as adsorbent for long for the removal of metal ions from solutions [29]. In our previous studies, removal of heavy metal ions like iron and chromium from MDEA solutions using polyacrylamide hydrogel (PAAM) was explored [30]. Though good removal was achieved, the polymeric PAAM adsorbents did not show good mechanical strength urged for more useful alternatives. To the best of our knowledge, no study has yet reported mechanically stable polyacrylamide sepiolite composite hydrogel beads for the removal of iron from aqueous lean MDEA solutions.

\section{Aim of the work}

The major aim of this research work is to explore the possible use of polyacrylamide (PAAM) hydrogel as effective adsorbent for the effective removal of iron from industrial lean MDEA solutions. Solvent plays a major role in polymerizing and cross linking to produce effective three dimensional network hydrogel to be used as adsorbent. Thus, PAAM hydrogel was prepared using three different organic solvents such as methanol, ethanol, dimethyl sulfoxide including deionized water to select the best to be used as adsorbent. The mechanical strength of the hydrogel is another useful parameter to be effectively used as adsorbents. Sepiolite, is a well-know clay used in this study to be added to increase the mechanical strength of the PAAM hydrogel. Sepiolite clay was treated with $0.1(\mathrm{~N})$ nitric acid solution to avoid any metal leaching to the MDEA solution. The composite PAAM hydrogel using nitric acid treated sepiolite clay of different loading was prepared to increase the mechanical strength to be used as adsorbent. The best selected PAAM sepiolite composite hydrogel was characterized using FTIR and SEM analysis. Adsorption studies were conducted using PAAM hydrogels using different solvents as well as PAAM sepiolite composite hydrogels to find best possible hydrogel for the removal of iron from industrial lean MDEA solvent.

\section{Materials and Methods}

\section{Materials and instrumentations}

All the chemicals were purchased from and used without any further purification. Chemicals used in this study are obtained (acrylamide, $\mathrm{C}_{3} \mathrm{H}_{5} \mathrm{NO}$; ammonium peroxodisulphate, $\left(\mathrm{NH}_{4}\right)_{2} \mathrm{~S}_{2} \mathrm{O}_{8^{\prime}} ; \mathrm{N}, \mathrm{N}^{\prime}$-methylenebisacrylamide, $\mathrm{C}_{7} \mathrm{H}_{10} \mathrm{~N}_{2} \mathrm{O}_{2}$ Merck, Germany/2(methacryloyloxy) ethyl aceto acetate, $\mathrm{C}_{10} \mathrm{H}_{14} \mathrm{O}_{5^{\prime}}$ Aldrich/ dimethyl sulfoxide dehydrated, $\mathrm{C}_{2} \mathrm{H}_{6} \mathrm{OS}$; VWR 
Chemicals, BDH and methanol, $\mathrm{CH}_{3} \mathrm{OH}_{\text {; }}$ ethanol, $\mathrm{C}_{2} \mathrm{H}_{5} \mathrm{OH}$; Fisher Scientific) from different sources. MDEA solvent containing 50 weight \% MDEA was provided by GASCO (Habshan, Abu Dhabi) and sepioliteclay was purchased from Sigma Aldrich, Germany.

Elemental analysis was carried out using Inductively Coupled Plasma Optical Emission Spectrometry (ICP-OES, Optima 8000, Perkin Elmer). Scanning Electron Microscopy (SEM) was carried out with FEI Quanta 200, The Netherland. The FTIR studies of lean MDEA, PAAM sepiolite clay composite before and after adsorption were carried out using FTIR, Nicolet, iS10, Thermo Scientific instrument using OMNIC software (number of scans 64 , resolution 4).

\section{Methods}

\section{Preparation of hydrogel using different solvents}

Hydrogel was prepared using acrylamide (AM) and 2-(methacryloyloxy) ethyl acetoacetate (AAEM) as monomer using free radical polymerization. $\mathrm{N}, \mathrm{N}$-methylenebisacrylamide (MBA) was used as cross-linker and ammonium peroxodisulphate (APS) was used as initiator. Methanol, ethanol, dimethyl sulfoxide (DMSO) and deionized water was used as solvent. Acrylamide (300.0 mg) was dissolved in $2 \mathrm{~mL}$ distilled water in $25 \mathrm{~mL}$ glass vials. $200 \mu \mathrm{L}$ AAEM was dissolved in $2 \mathrm{~mL}$ methanol/ethanol/DMSO/water was added to AM solution. The mixture was stirred for $2 \mathrm{~h}$ to get homogenous mixture. Then, $300 \mu \mathrm{L}$ saturated MBA was added as cross linker. Finally, $100 \mu \mathrm{L} 10$ weight\% APS was added to initiate polymerization reaction. The mixture was transferred into a water bath at $60^{\circ} \mathrm{C}$ for $2 \mathrm{~h}$ and kept at room temperature for $24 \mathrm{~h}$ to ensure complete polymerization. The resulting polymer hydrogel was cut into small pieces and immersed in deionized water to remove any unreacted monomers. Finally, the hydrogel was placed in an oven at $45-50^{\circ} \mathrm{C}$ for $15 \mathrm{~min}$ before use as adsorbent.

\section{Preparation of polyacrylamide hydrogel using different amount of sepiolite clay}

Acrylamide $(300.0 \mathrm{mg}$ ) was dissolved in $2 \mathrm{~mL}$ deionized water. Predetermined amount of $0.1(\mathrm{~N})$ nitric acid treated sepiolite clay was added and mixed to get homogeneous solution. MBA $(300 \mu \mathrm{L})$ and APS $(100 \mu \mathrm{L})$ was added subsequently to the acrylamide solution. The mixture was transferred into a water bath at $60^{\circ} \mathrm{C}$ for $2 \mathrm{~h}$ followed by $24 \mathrm{~h}$ at room temperature. The composite hydrogel was washed with distilled water and oven dried for 15 minutes at $45-50^{\circ} \mathrm{C}$ before use as adsorbent.

\section{Analysis of iron in lean MDEA}

The iron content in lean MDEA was determined by Inductively Coupled Plasma Optical Emission Spectroscopy (ICP-OES, Optima 8000; Perkin Elmer) and found to be 1417 $\mu \mathrm{g} / \mathrm{g}()$. The argon flow rate was $12 \mathrm{~L} / \mathrm{min}$ and air flow rate $(1.2$ $\mathrm{L} / \mathrm{min}$ ). Internal standards yttrium (1.0 ppm) was added to correct the physical interferences of aqueous-organic mixture on $2 \%$ nitric acid as blank, standards and MDEA solution [3].

\section{Batch adsorption study}

Iron adsorption from lean MDEA was conducted in batch mode in $50 \mathrm{~mL}$ stoppered conical flasks containing $1.0 \mathrm{~g} \mathrm{()} \mathrm{of}$ adsorbent in $10 \mathrm{~mL}$ lean MDEA solution () at $25^{\circ} \mathrm{C}$. The flasks were placed on a water bath shaker (Dihan, Korea) at $140 \mathrm{rpm}$ for $24 \mathrm{~h}$ to attain equilibrium. The supernatants were extracted and analyzed using ICP-OES for equilibrium concentration ().

The amount of contaminants removed using batch equilibrium study was calculated as:

$\%$ Removal $=\frac{\left(C_{0}-C_{e}\right)}{C_{0}} \times 100 \%$

$C_{0}=$ Initial concentration of iron in lean MDEA $(\mu \mathrm{g} / \mathrm{L})$

$\mathrm{C}_{\mathrm{e}}=$ residual concentration of iron in lean MDEA at equilibrium $(\mu \mathrm{g} / \mathrm{L})$

$$
\mathrm{q}_{\mathrm{e}}=\left(\mathrm{C}_{\mathrm{o}}-\mathrm{C}_{\mathrm{e}}\right)\left(\frac{\mathrm{V}}{\mathrm{M}}\right)
$$

$\mathrm{q}_{\mathrm{e}}$ Uptake capacity of iron adsorbed per unit mass of hydrogel at equilibrium $(\mu \mathrm{g} / \mathrm{g})$

$\mathrm{V}=$ volume of lean MDEA $(\mathrm{mL})$

$M=$ mass of adsorbent $(\mathrm{g})$

\section{Results and Discussions \\ Polyacrylamide hydrogels using different solvents}

The PAAM hydrogels prepared using different solvents were found to have different texture. The produced hydrogels are shown in Figure 1. Hydrogels prepared from methanol, ethanol, DMSO and water were cut into pieces and used for adsorption studies. PAAM hydrogel prepared using methanol was colorless. While, hydrogel prepared using ethanol was found to be milky with good textural appearance and found to be less swelled in lean MDEA. However, it was unstable and became softer when added to lean MDEA solvent. Hydrogel produced using DMSO solvent was found to be fast gelling during polymerization and yellowish in color and best in mechanical strength and less swelling. While, PAAM hydrogel prepared using water was best to use as less corrosive as compare to other organic solvents.

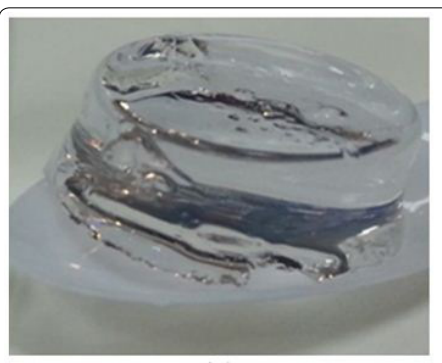

(a)

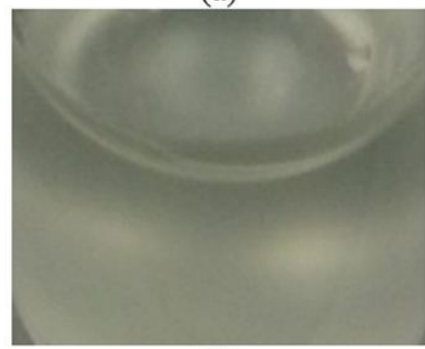

(c)

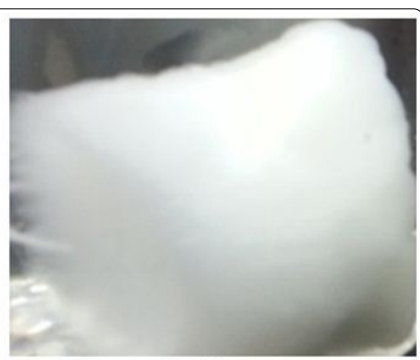

(b)

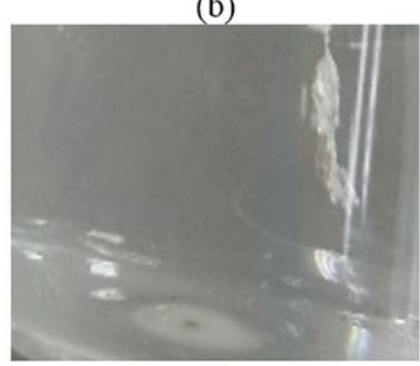

(d)
Figure 1. PAAM hydrogel prepared using(a) methanol, (b) ethanol, (c) DMSO and (d) water as solvent. 


\section{Polyacrylamide hydrogels with different clay loading}

Composite PAAM hydrogel using 0.1 (N) nitric acid treated sepiolite clay having different amount are shown in Figure 2. It was observed that composite hydrogels were denser with increasing clay loading.

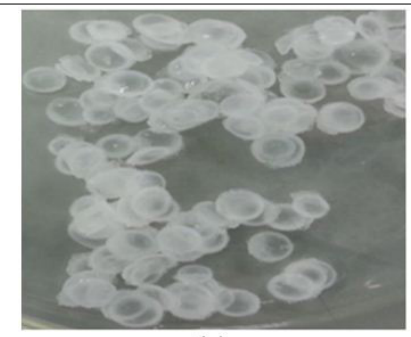

(a)

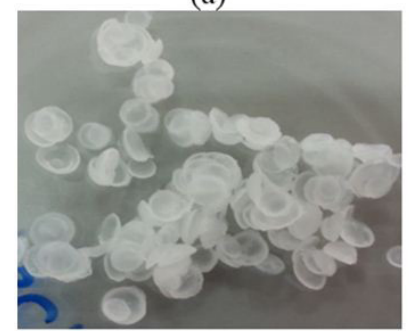

(c)

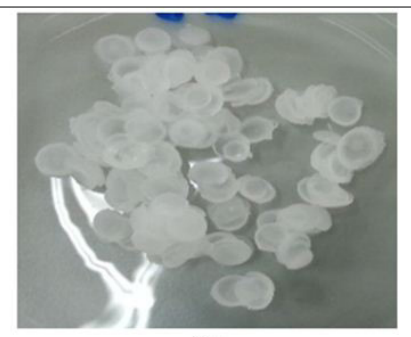

(b)

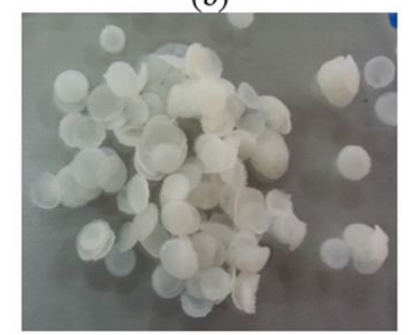

(d)
Figure 2. PAAM clay composite hydrogel prepared using (a) 3.125 \% clay, (b) $6.25 \%$ clay, (c) $9.375 \%$ clay and (d) $12.5 \%$ clay.

\section{SEM analysis}

The PAAM composite hydrogel beads with different weight $\%$ of sepiolite clay were observed using Scanning Electron Microscopy (SEM) to understand surface properties. The SEM images are shown in Figure 3.Composite PAAM hydrogel with different amount of sepiolite was found to be heterogeneous with internal cavity. As the amount clay increased in polyacrylamide matrix, the surface morphology was changed. The surface became more homogeneous near to outer surface, while at the center of the bead it was found to be more compact. In Figure 3 (b), it can be seen that there is well-distributed porosity at the center. At higher clay loadings, Figures 3 ( $c$ and d) the center of the beads became denser and compact, and there was no distinct improvement in surface porosity.

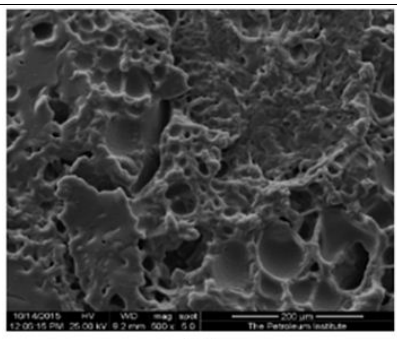

(a)

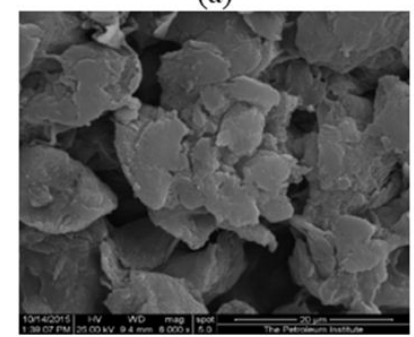

(c)

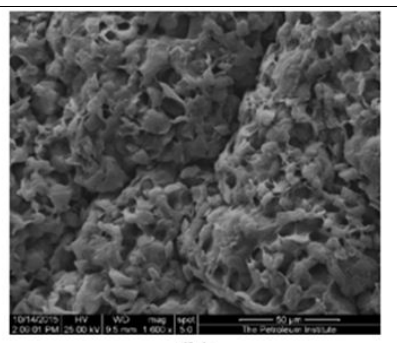

(b)

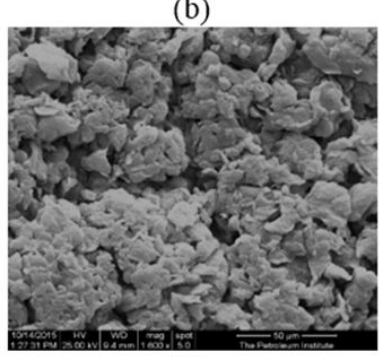

(d)
Figure 3. SEM micrographs of (a) PAAM hydrogel in water (b) composite PAAM hydrogel $3.125 \%$ sepiolite (c) PAAM-9.375\% sepiolite(d)PAAM-9.375\% sepiolite.

\section{FTIR analysis}

Figure 4 shows the FTIR spectra of lean MDEA and PAAM sepiolite clay composite hydrogel before and after adsorption. The composite hydrogel spectrum showed a peak at 1020 $\mathrm{cm}^{-1}$ in addition to PAAM characteristic peaks [13]. The peak represents $\mathrm{Si}-\mathrm{OH}$ coming from sepiolite clay. In PAAM hydrogel spectrum, the broad peaks centered at $3295 \mathrm{~cm}^{-1}$ represents $\mathrm{OH}$ stretching vibration resulted from the residual water molecules in the hydrogel. Also, $\mathrm{NH}_{2}$ stretching vibration at the same region increased the intensity of the peak. The peak at $1650 \mathrm{~cm}^{-1}$ is attributed to $\mathrm{C}=\mathrm{O}$ stretching. The peaks at 1412 and $1446 \mathrm{~cm}^{-1}$ are due to stretching vibrations of the $\mathrm{C}-\mathrm{N}$ bond and $\mathrm{CH}_{2}$ bending vibrations, respectively. While, in lean MDEA and in adsorbed hydrogel sample similar peaks were determined. After adsorption, new IR peak appear at $1451 \mathrm{~cm}^{-1}$ indicates the adsorption of iron on PAAM composite hydrogel surface [31].

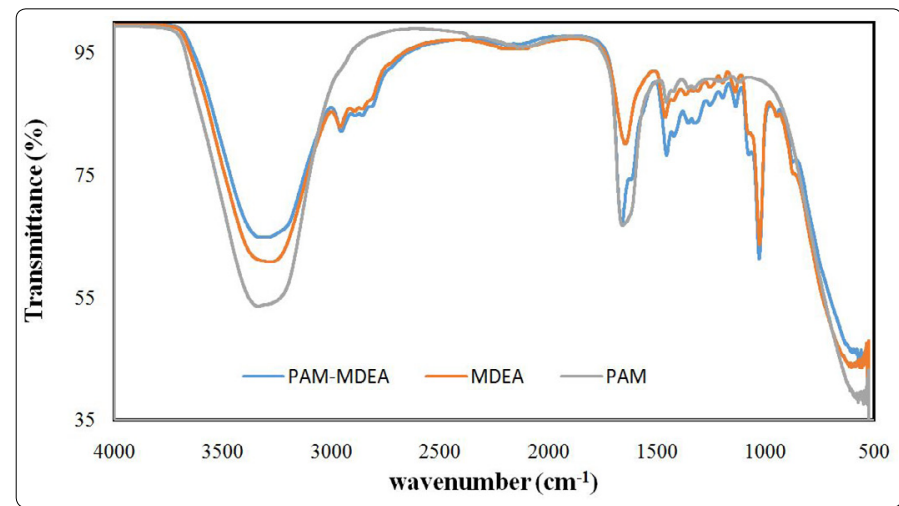

Figure 4. FTIR spectra of MDEA and polyacrylamide hydrogel before and after adsorption in MDEA

\section{Adsorption studies}

\section{Polyacrylamide hydrogel using different solvents}

The uptake capacity and \% removal of iron on PAAM hydrogel prepared using different solvents are tested to remove iron from lean MDEA as shown in Figure 5. Metanol (1), ethanol (2), DMSO (3) and deionized water (4) was used in this study. The \% iron removal as well as uptake capacity using methanol solvent to prepare PAAM hydrogel was found to be $23.19 \%$ and3.286 $\mu \mathrm{g} / \mathrm{g}$, respectively. The removal efficiency was found almost similar using DMSO solvent (21.0\% iron removal having uptake capacity of $2.975 \mu \mathrm{g} / \mathrm{g}$ ). While, PAAM hydrogel prepared using ethanol gave the lowest iron removal (14.21\%) and subsequently minimum uptake capacity $(2.013 \mu \mathrm{g} / \mathrm{g})$. PAAM hydrogel prepared using water was found to be best for the removal of iron $(24.75 \%$ having uptake capacity $3.286 \mu \mathrm{g} / \mathrm{g}$ ) from lean MDEA [30]. Therefore, it was used further to prepare composite hydrogel for the adsorption of iron from lean MDEA solvent. 


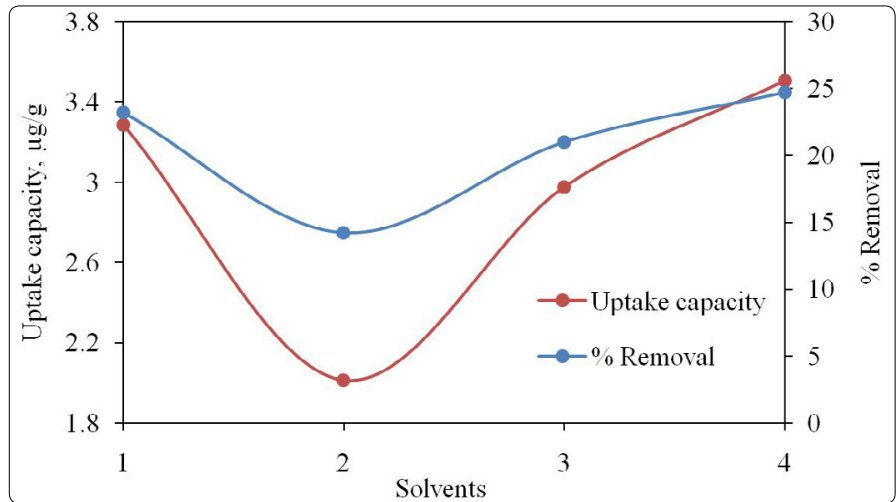

Figure 5. Effect of different solvent(1 methanol; 2 ethanol; 3 dimethyl sulfoxide and 4 deionized water) on uptake capacity and $\%$ removal of iron using $1.0 \mathrm{~g}$ of each PAAM hydrogel in $10 \mathrm{~mL}$ lean MDEA for $24 \mathrm{~h}$ at $298 \mathrm{~K}$.

\section{Polyacrylamide composite hydrogel using different clay loading}

To increase the mechanical strength of the hydrogel PAAM-nitric acid treated sepiolite clay composite was used. It was evident that sepiolite can be effectively used as adsorbent to remove metal ions from solutions and with increasing amount of sepiolite in solution decreases the equilibrium metal ions concentrations [32]. Thus, uptake capacity as well as \% removal should be higher with increasing sepiolite loading. The uptake capacity and \% removal of iron on increasing amount of sepiolite loaded PAAM hydrogels is shown in Figure 6. It was observed that both \% iron removal as well as uptake capacity was increased with increasing clay content and remain almost constant with $12.5 \%$ of sepiolite clay loading. The \% iron removal was increased from 26.25$45.15 \%$ with sepiolite loading increased from 3.125-12.5 weight \%. The uptake capacity was also found to be increased from 3.125-6.397 $\mu \mathrm{g} / \mathrm{g}$ with increase in sepiloite loading on PAAM hydrogel matrix.

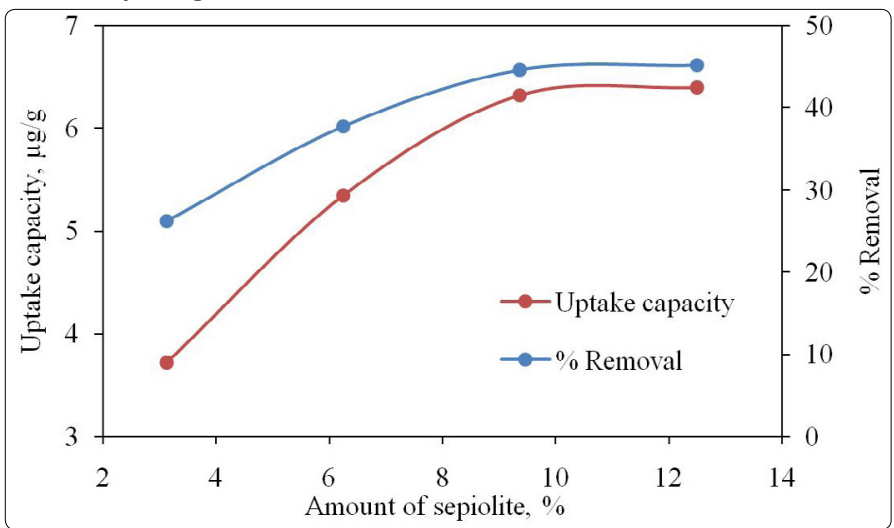

Figure 6. Effect of clay loading on uptake capacity and \% removal of iron using $1.0 \mathrm{~g}$ of each PAAM- sepiolite composite hydrogel in $10 \mathrm{~mL}$ lean MDEA for $24 \mathrm{~h}$ at $298 \mathrm{~K}$.

\section{Conclusion}

This research work investigated the preparation of PAAM hydrogel using different solvent and used as an adsorbent for the removal of iron from industrial lean MDEA. Among methanol/ethanol/DMSO/water used, PAAM hydrogel prepared using water was found to be best for the removal of iron
( $24.75 \%$ having uptake capacity $3.50 \mu \mathrm{g} / \mathrm{g}$ using $1.0 \mathrm{~g}$ PAAM hydrogel) from lean MDEA solvent. SEM and FTIR analysis were carried out using $0.1(\mathrm{~N})$ nitric acid treated sepiolite composite PAAM to characterize the hydrogel. The $12.5 \%$ loaded sepiolite PAAM composite hydrogel exhibited the highest percentage removal of iron from industrial lean MDEA solvent.

\section{Acknowledgement}

The authors are grateful to the Gas Research Centre, The Petroleum Institute, Abu Dhabi for funding the project (GRC 006). Sincere thanks to GASCO Company (Habshan, Abu Dhabi) for their co-operation and support.

\section{References}

1. Mandal BP, Biswas AK, Bandopadhyay SS. Selective adsorption of $\mathrm{H}_{2} \mathrm{~S}$ from gas streams containing $\mathrm{H}_{2} \mathrm{~S}$ and $\mathrm{CO}_{2}$ into aqueous solutions of $\mathrm{N}$-methyldiethanolamine and 2-amino-2-methyl-1-propanol. Sep. Puri. Tech. 2004; 35(3): 191-202. doi: 10.1016/S1383-5866(03)00139-4

2. Lu JG, Zheng YF, He DL. Selective absorption of $\mathrm{H}_{2} \mathrm{~S}$ from gas mixtures into aqueous solution of blended amines of methyldiethanolamine and 2-tertiarybutylamino-2-ethoxyethanol in a packed column. Sep. Puri. Tech. 2006; 52(2): 209-217. doi: 10.1016/j.seppur.2006.04.003

3. Nielsen RB, Lewis KR. Corrosion in Refinery Amine Systems, Corrosion/95; NACE International Houston. 1995; 571.

4. Rooney PC, DuPart MS, Bacon TR. Effect of heat stable salts on MDEA solution corrosivity, Hydro. Proc. 1997; 76: 65-68.

5. Keller $A E$, Kammiller RM, Veatch FC, Cummings AL, Thompsen JC, Mecum SM. Heat-stable salt removal from amines by the HSSX process using ion exchange. Proceedings of 42nd Annual Laurance Reid Gas Conditioning Conference. The University of Oklahoma OK. 1992; 61-92.

6. Pal $\mathrm{P}$, AbuKashabeh $\mathrm{A}, \mathrm{Al}-\mathrm{Asheh} \mathrm{S}$, Banat $\mathrm{F}$. Role of aqueous methyldiethanolamine (MDEA) as solvent in natural gas sweetening unit and process contaminants with probable reaction pathway. J. Nat. Gas Sci. Eng. 2015; 24: 124-131. doi: 10.1016/j.jngse.2015.03.007

7. Pal $P$, Banat $F$. Comparison of heavy metal ions removal from industrial lean amine solvent using ion exchange resins and sand coated with chitosan. J. Nat. Gas Sci. Eng. 2014; 18: 227-236. doi: 10.1016/j.jngse.2014.02.015

8. Pal P, Banat F. Comparison of thermal degradation between fresh and industrial aqueous methyldiethanolamine with continuous injection of $\mathrm{H}_{2} \mathrm{~S} / \mathrm{CO}_{2}$ in high pressure reactor. J. Nat. Gas Sci. Eng. 2016; 29: 479-487. doi: 10.1016/j.jngse.2016.01.037

9. Ross TK, Pearson C. The corrosion of mild steel by ethanolamine solutions. Corro. Sci. 1964; 4(1-4): 449-452. doi: 10.1016/0010-938X(64)90046-0

10. Alhseinat $E$, Pal $P$, Keewan $M$, Banat F. Foaming study combined with physical characterization of aqueous MDEA gas sweetening solutions. J. Nat. Gas Sci. Eng. 2014; 17: 49-57. doi: 10.1016/j.jngse.2013.12.004

11. Meng $H, L i H, L i C X$. Synthesis of ionic liquid using a four-compartment configuration electrodialyzer. J. Mem. Sci. 2008; 318(1-2): 1-4. doi: 10.1016/j.memsci.2008.02.020

12. Cheryan M, Parekh SR. Separation of glycerol and organic acids in model ethanol stillage electrodialysis and precipitation. Proc. Biochem. 1995; 30: 17-23. doi: 10.1016/0032-9592(95)87003-2

13. Hong $M$, Shuang $Z$, Chunxi L, Liangshi L. Removal of heat stable salts from aqueous solutions of $\mathrm{N}$-methyldiethanolamine using a specially designed three-compartment configuration electrodialyzer. J. Mem. Sci. 2008; 322(2): 436-440. doi: 10.1016/j.memsci.2008.05.072

14. TangSCN, LoIMC, MakMSH.ComparativeStudy oftheadsorptionselectivity of $\mathrm{Cr}(\mathrm{VI})$ onto cationic hydrogels with different functional groups. Wat. Air Soil Pollu. 2012; 223(4): 1713-1722. doi: 10.1007/s11270-011-0977-4 
15. Khan M, Lo IMC. Removal of ionizable aromatic pollutants from contaminated water using nano $-\mathrm{Fe}_{2} \mathrm{O}_{3}$ based magnetic cationic hydrogel: sorptive performance, magnetic separation and reusability. J. Hazard. Mater. 2017; 322: 195-204. doi: 10.1016/j.jhazmat.2016.01.051

16. Merino S, Martín C, Kostarelos K, Prato M, Vazquez E. Nanocomposite hydrogels: 3D polymer-nanoparticle synergies for on-demand drug delivery. ACS Nano. 2015; 9(5):4686-4697. doi: 10.1021/acsnano.5b01433

17. Ozay O, Ekici S, Baran Y, Aktas N, Sahiner N. Removal of toxic metal ions with magnetic hydrogels. Wat. Res. 2009; 43(17): 4403-4411. doi: 10.1016/j.watres.2009.06.058

18. Zhu $Y$, Zheng $Y$, Wang F, Wang A. Monolithic super macroporous hydrogel prepared from high internal phase emulsions (HIPEs) for fast removal of $\mathrm{Cu}^{2+}$ and $\mathrm{Pb}^{2+}$. Chem. Eng. J. 2016; 284: 422-430.

19. Tang SCN, Wang P, Yin K, Lo IMC. Synthesis and application of magnetichydrogel for $\mathrm{Cr}(\mathrm{VI})$ removal from contaminated water. Environ. Eng. Sci. 2010; 27(11): 947-954. doi: 10.1089/ees.2010.0112

20. Ahmed EM. Hydrogel: preparation, characterization, and applications: a review. J. Adv. Res. 2015; 6(2): 105-121. doi: 10.1016/j.jare.2013.07.006

21. Bekiari V, Sotiropoulou $M$, Bokias $G$, Lianos $P$. Use of $\operatorname{poly}(N, N$ dimethylacrylamide-co-sodium acrylate) hydrogel to extract cationic dyes and metals from water. Colloids Surf.A. 2008; 312: 214-218.

22. Kasgoz H, Ozgumus S, Orbay M. Modified polyacrylamide hydrogels and their application in removal of heavy metal ions. Poly. 2003; 44(6): 1785-1793. doi: 10.1016/S0032-3861(03)00033-8

23. Trakulsujaritchok T, Noiphom N, Tangtreamjitmun N, Saeeng R. Adsorptive features of poly(glycidylmethacrylateco-hydroxyethyl methacrylate): effect of porogen formulation on heavy metal ion adsorption. J. Mater. Sci. 2011; 46(16): 5350-5362. doi: 10.1007/s10853-011-5473-0

24. Raeburn J, Mendoza CC, Cattoz BN, Little MA, Terry AE, Cardoso AZ, Griffiths PC, Adams DJ. The effect of solvent choice on the gelation and final hydrogel properties of Fmoc-diphenylalanine. Soft Mat. 2015; 11: 927-935. doi: 10.1039/C4SM02256D
25. Zhang $X$, Yang $Y$, Chung T. Effect of mixed solvents on characteristics of poly( $N$-isopropylacrylamide) gels. Lang. 2002; 18 (7): 2538-2542. doi: 10.1021/la011410j

26. Chiew CSC, Yeoh HK, Pasbakhsh P, Krishnaiah K, Poh PE, Tey BT, Chan ES. Halloysite/alginate nanocomposite beads: kinetics, equilibrium and mechanism for lead adsorption. Appl. Clay. Sci. 2016; 119: 301-310. doi: 10.1016/j.clay.2015.10.032

27. Zhang H, Pang X, Qi Y. pH-Sensitive graphene oxide/sodium alginate/ polyacrylamide nanocomposite semi-IPN hydrogel with improved mechanical strength. RSC Adv. 2015; 5: 89083-89091. doi: 10.1039/ C5RA19637J

28. Khan M, Lo IMC. A holistic review of hydrogel applications in the adsorptive removal of aqueous pollutants: Recent progress, challenges, and perspectives. Water Res. 2016; 106: 259-271. doi: 10.1016/j. watres.2016.10.008

29. Padilla-Ortega E, Leyva-Ramos R, Mendoza-Barron J, GuerreroCoronado RMA, Jacobo-Azuara A, Aragon-Pina A. Adsorption of Heavy Metal Ions from Aqueous Solution onto Sepiolite. Ads. Sci. Tec. 2011; 29(6): 569-584. doi: 10.1260/0263-6174.29.6.569

30. Pal P, Banat F. Removal of contaminants from industrial lean amine solvent using polyacrylamide hydrogels optimized by response surface methodology. Ads. Sci. Tec. 2015; 33(1): 9-24. doi: 10.1260/02636174.33.1.9

31. Tandon PK, Shukla RC, Singh SB. Removal of arsenic (III) from water with clay-supported zerovalent iron nanoparticles synthesized with the help of tea liquor. Ind. Eng. Chem. Res. 2013; 52(30): 10052-10058. doi: 10.1021/ie400702k

32. Kara M, Yuzer $H$, Sabah E, Celik MS. Adsorption of cobalt from aqueous solutions onto sepiolite. Wat. Res. 2003; 37(1): 224-232. doi: 10.1016/ s0043-1354(02)00265-8 